\title{
Atypical Antipsychotics and a Src Kinase Inhibitor (PPI) Prevent Cortical Injury Produced by the Psychomimetic, Noncompetitive NMDA Receptor Antagonist MK-80 I
}

\author{
Jon Dickerson' and Frank R Sharp*,1,2 \\ 'Neurosciences Graduate Program, University of Cincinnati, Cincinnati, OH, USA; ${ }^{2}$ Department of Neurology and the Neurosciences Program, \\ M.I.N.D. Institute, University of California at Davis, Sacramento, CA, USA
}

\begin{abstract}
Noncompetitive N-methyl-D-aspartate (NMDA) receptor antagonists such as phencyclidine, ketamine, and MK-80I produce schizophrenia-like psychosis in humans. The same NMDA antagonists injure retrosplenial cortical neurons in adult rats. We examined the effects of atypical antipsychotics and an inhibitor of nonreceptor tyrosine kinase pp60 (Src) on the cortical injury produced by MK80I. An atypical antipsychotic (either clozapine, ziprasidone, olanzapine, quetiapine, or risperidone) or vehicle was administered to adult female Sprague-Dawley rats. PPI (Src inhibitor), PP3 (nonfunctional analog of PPI) or vehicle (DMSO) was administered to another group of animals. After pretreatment, animals were injected with MK-80 I, killed $24 \mathrm{~h}$ after the MK-80 I, and injury to retrosplenial cortex assessed by neuronal Hsp70 protein expression. All atypical antipsychotics examined significantly attenuated MK-80I-induced cortical damage. PPI protected compared to vehicle, whereas PP3 did not protect. The ED50s (decrease injury by 50\%) were as follows: PPI $<0.1 \mathrm{mg} / \mathrm{kg}$; olanzapine $0.8 \mathrm{mg} / \mathrm{kg}$; risperdal I mg/kg; clozapine $3 \mathrm{mg} / \mathrm{kg}$; ziprasidone $32 \mathrm{mg} / \mathrm{kg}$; and quetiapine $45 \mathrm{mg} / \mathrm{kg}$. The data show that the atypical antipsychotics tested as well as a Src kinase inhibitor prevent the injury produced by the psychomimetic MK-80 I, and the potency of the atypical antipsychotics for preventing cortical injury was roughly similar to the potency of these drugs for treating psychosis in patients.

Neuropsychopharmacology (2006) 3 I, |420- |430. doi:| 0. I038/sj.npp. I 300878; published online 17 August 2005
\end{abstract}

Keywords: NMDA receptors; MK-80 I; phencyclidine; atypical antipsychotics; psychosis; dopamine receptors; Src; schizophrenia

\section{INTRODUCTION}

Noncompetitive $N$-methyl-D-aspartate (NMDA) antagonists, including phenyclidine (PCP), ketamine, and MK-801, produce psychosis in healthy humans (Breier et al, 1997; Javitt and Zukin, 1991; Krystal et al, 1999a; Malhotra et al, 1996; Vollenweider et al, 2000), and precipitate psychosis in compensated schizophrenics (Lahti et al, 1995; Malhotra et al, 1997; Tamminga, 1999). Animal studies showed that the noncompetitve NMDA antagonists produce vacuolization of neurons in retrosplenial cingulate cortex (posterior cingulate cortex) of adult rats (Olney et al, 1989) that could be blocked by GABAergic drugs (Olney et al, 1991). The vacuolated, injured neurons expressed the Hsp70 heat shock protein indicating that protein denaturation had

\footnotetext{
* Correspondence: Professor FR Sharp, Department of Neurology and the Neurosciences Program, M.I.N.D. Institute, University of California at Davis, 2805 50th Street, Room 2416, Sacramento, CA 95817, USA, Tel: + | 916703 0368, Fax: + | 9167030369 ,

E-mail: frsharp@ucdavis.edu

Received 24 March 2005; revised 5 May 2005; accepted 12 July 2005 Online publication: 19 July 2005 at http://www.acnp.org/citations/ Npp07| 905050 198/default.pdf
}

occurred in the neurons but that they would survive (Sharp et al, 1991, 1992, 1994a, 1999). The observation that PCPlike drugs produce psychosis in people and produced neuronal injury in limbic cortex of rodents implied that the neurotransmitters and circuits that mediate limbic cortex injury in rodents may be similar to those that mediate PCPlike psychosis in people (Farber et al, 2002; Olney, 1994; Olney et al, 1999; Sharp et al, 2001).

This proposal was supported by findings showing that antipsychotic drugs blocked the limbic cortical injury in rodents produced by PCP, ketamine, and MK-801 (Farber et al, 1993; Olney and Farber, 1994; Sharp et al, 1992). Haloperidol blocked the injury to retrosplenial cortex produced by NMDA-receptor antagonists in rats (Sharp et al, 1992, 1993, 1994a, b). These findings prompted studies of atypical antipsychotics, including clozapine and olanzapine, which also blocked the cortical injury produced by NMDA antagonists in rodents (Farber et al, 1993, 1996; Olney and Farber, 1994; Sharp et al, 1994b). Therefore, it appeared as though drugs that decrease psychosis in people all block the limbic cortical injury produced by NMDAreceptor antagonists in rodents. The present study therefore postulated that the currently used atypical antipsychotics 
like olanzapine, risperidone, clozapine, ziprasidone, and quetiapine should block the injury produced by NMDAreceptor antagonists in rodent brain. The results generally confirm this hypothesis, and also show that the potency for blocking cortical injury in rats is similar to the potency of the drugs for treating psychosis in humans.

As result of recent studies showing that the downstream effects of NMDA receptors are mediated by Src kinases (Salter and Kalia, 2004), we tested a Src antagonist in the MK-801/PCP cortical injury model. Indeed, the Src antagonist protects against MK-801-mediated injury, which might suggest a role for Src kinases mediating PCP/ketamine/MK801 behaviors in humans. Since some drugs block MK-801mediated injury that are not antipsychotics, including calcium channel blockers and antimuscarinics and selective serotonin reuptake antagonists (Sharp et al, 1994b; Tomitaka et al, 2000a), it is not clear whether Src antagonists might or might not affect psychosis.

\section{MATERIALS AND METHODS}

The National Institutes of Health Guide for the Care and Use of Laboratory Animals was followed when performing these experiments. Adult female Sprague-Dawley rats (1214 weeks old, 226-250 g, Charles River Labs, Wilmington, MA, USA) were used for all experiments $(n=198)$. Females were used instead of males because the injury produced by PCP, ketamine, and MK-801 is more reproducible in female compared to male rodents (Auer, 1996; Sharp et al, 1994a). Adults were used because NMDA antagonists do not produce cortical injury in neonatal and very young rodents (Auer, 1996; Farber et al, 1995; Nakki et al, 1996).

\section{Atypical Antipsychotics Clozapine and Ziprasidone (Intraperitoneal (i.p.))}

The effects of systemic, i.p. clozapine and ziprasidone on the injury produced by systemic MK-801 were investigated in three groups of animals. The first group of animals, which was paired with the second and third groups, was injected intraperitoneally (i.p.) with vehicle followed $1 \mathrm{~h}$ later by MK-801 (1 mg/kg i.p.). The second group of animals was given clozapine followed $1 \mathrm{~h}$ later by MK-801 $(1 \mathrm{mg} / \mathrm{kg}$ i.p.). The third group of animals received ziprasidone followed $1 \mathrm{~h}$ later by MK-801 ( $1 \mathrm{mg} / \mathrm{kg}$ i.p.). MK-801 was dissolved in $0.9 \%$ normal saline. Clozapine and ziprasidone were dissolved in dimethylsulfoxide (DMSO). The dosages were adjusted to produce a dose-response curve for each drug. The $1 \mathrm{mg} / \mathrm{kg}$ MK-801 dose and $24 \mathrm{~h}$ survivals were chosen based on maximum HSP70 immunoreactivity in brain at $24 \mathrm{~h}$ post-MK-801 administration (Sharp et al, 1991).

\section{Atypical Antipsychotics Quetiapine, Olanzapine and Risperdone (Gastric Intubation (g.i.))}

Experiments were performed to determine if the antipsychotics quetiapine, olanzapine, and risperidone had any neuroprotective effect when administered prior to MK-801. These drugs were used as a group because they had no intravenous or intramuscular formulation and they were insoluble in anything we tested. Each antipsychotic drug was therefore ground into a fine powder with a mortar and pestle and then suspended in water. For the administration of these drugs, the rats were briefly anesthetized with isoflurane ( $5 \%$ for $3 \mathrm{~min}$ ). The suspended drug was fed to the rats by g.i. using an apparatus consisting of a winged infusion set, with the needle cutoff, attached to a $1 \mathrm{ml}$ syringe. The total volume given to each animal was $400 \mu$ l.

For these studies of atypical antipsychotics, the animals were divided into four groups. The first group was the control group, and each animal in this group was paired with an animal from each of the rest of the groups. Control animals were administered vehicle $(400 \mu$ of water via g.i.) followed $2 \mathrm{~h}$ later by MK-801 (1 mg/kg) given i.p. The second group was given olanzapine followed by MK-801 $(1 \mathrm{mg} / \mathrm{kg}$ i.p.) $2 \mathrm{~h}$ later. The third group was given risperidone followed $2 \mathrm{~h}$ later by MK-801 ( $1 \mathrm{mg} / \mathrm{kg}$ i.p.). The fourth group was given quetiapine followed $2 \mathrm{~h}$ later by MK-801 (1 mg/kg i.p.).

\section{Src Inhibitor}

Experiments were performed to determine if an inhibitor of nonreceptor tyrosine kinase pp60 (Src) protected when administered prior to MK-801.The effects of systemic PP1 (Src inhibitor) on the injury produced by systemic MK-801 were then investigated in three groups of animals. The control group of animals $(n=7)$, which was paired with the second and third groups, was injected with vehicle (DMSO i.p.) followed $1 \mathrm{~h}$ later by MK-801 ( $1 \mathrm{mg} / \mathrm{kg}$ i.p.). The second group of animals was given PP1 $(0.1,1$, and $10 \mathrm{mg} / \mathrm{kg}$ i.p.) $(n=7$ for each dose) followed $1 \mathrm{~h}$ later by MK-801 $(1 \mathrm{mg} / \mathrm{kg}$ i.p.). The third group of animals received PP3 (a nonfunctional PP1 analog) $(0.1,1$, and $10 \mathrm{mg} / \mathrm{kg}$ i.p.) $(n=7$ for each dose, except for $1 \mathrm{mg} / \mathrm{kg} n=6$ ) followed $1 \mathrm{~h}$ later by MK-801 ( $1 \mathrm{mg} / \mathrm{kg}$ i.p.). MK-801 was dissolved in $0.9 \%$ normal saline. PP1 and PP3 were dissolved in DMSO. The dosages were adjusted in an attempt to form a dose-response curve. PP1 is synthetic pyrazolopyrimidine, 4-amino-5-(4-methylphenyl)-7-(t-butyl)pyrazolo [3,4-d] pyrimidine (PP1) and is a novel, potent, and selective inhibitor of Src family tyrosine kinases (SFK) whereas PP3 is an inactive analogue of PP1 (Akiyama et al, 2004; Zhou and Menko, 2002).

\section{Hsp70 Immunocytochemical Assessment of Neuronal Injury}

At 1 day $(24 \mathrm{~h})$ after systemic administration of MK-801 $(1 \mathrm{mg} / \mathrm{kg})$, animals were briefly anesthetized with ketamine and xylazine $(20 \mathrm{mg} / \mathrm{kg})$ and deeply anesthetized animals were then perfused within $5 \mathrm{~min}$ through the ascending aorta with normal saline $(0.9 \%)$ and then $300 \mathrm{ml}$ of $4 \%$ paraformaldehyde in $0.1 \mathrm{M}$ sodium phosphate buffer (PB; $\mathrm{pH}$ 7.4). This brief period of anesthesia does not produce cortical injury (Sharp et al, 1991). This 24-h survival period was used for all animals whether they received systemic administration of drug or vehicle or oral administration of drug or vehicle. The brains were removed and immersed in fixative for $2 \mathrm{~h}$ followed by cryo-protection in $30 \%$ sucrose solution in PB for 2 days or until they sank. In all, $50 \mu \mathrm{m}$ thick frozen coronal sections were cut with a Leitz sledge microtome. 
HSP70 immunohistochemistry was performed as previously described (Tomitaka et al, 2000a,b) using the Vectastatin Elite $\mathrm{ABC}$ kit (Vector Laboratories, Burlingame, CA, USA). Briefly, brain sections were washed several times in $\mathrm{PB}$ and blocked for $2 \mathrm{~h}$ using $\mathrm{PB}$ containing $2 \%$ goat serum, $0.2 \%$ Triton $\mathrm{X}-100$, and $0.1 \%$ bovine serum albumin (GS-PB). The sections were then treated with primary antibody to HSP70 (StressGen Biotechnologies, Victoria, Canada) at a $1: 5000$ dilution in GS-PB for $24 \mathrm{~h}$. The sections were then washed three times for 10 min each with PB and subsequently incubated with the secondary antibody (biotinylated goat anti-rabbit immunoglobulin $\mathrm{G}(\mathrm{IgG})$ absorbed with goat serum) at a 1:500 dilution in GS-PB for $2 \mathrm{~h}$. Detection of HSP70 protein was performed using avidinbiotin-peroxidase and diaminobenzidine (Sigma, St Louis). The sections were washed three times in $\mathrm{PB}$ and mounted on slides. Brains from the controls and experimental animals for each study were processed in parallel to help reduce variability related to the immunostaining procedures.

HSP70 protein was used to detect injury for several reasons. It has been demonstrated in injured, vacuolated neurons and Hsp70 immunostaining has been used as a marker for neuronal injury following administration of MK801, ketamine and phencyclidine (PCP) (Olney et al, 1991; Sharp et al, 1991, 1992, 1994a; Nakki et al, 1995, 1996; Rajdev et al, 1998; Tomitaka et al, 2000a, b). Hsp70 protein is induced by the presence of denatured proteins in cells and is generally induced in cells that will survive an injury (Sharp et al, 1999). Hsp70 may be a preferred marker of neuronal injury compared to neuronal vacuolization since vacuolization is only seen in aldehyde-fixed brain and not in fresh frozen brain sections - the aldehyde fixation possibly fixing denatured proteins that can result in vacuoles (Auer, 1994; Auer and Coulter, 1994).

\section{Cell Counting and Statistics}

Cell counts were performed as previously described (Tomitaka et al, 2000b). Counts were performed at $\times 100$ magnification within a $0.1 \mathrm{~mm}^{2}$ area centered over layer III in the retrosplenial cortices using a microcomputer-imaging device (MCID, London, Canada). Every third section was counted through the entire anterior posterior dimension of the retrosplenial cortex in every animal ( $\sim 6$ sections per animal). Counts were performed on both retrosplenial cortices on each section so that there were 12 counts per such subject. The counting area was always centered precisely over the middle one-third of each retrosplenial cortex and encompassed layers 1-4 of the cortex. The areas counted were similar to those shown in Figures 1a and 2a. Only Hsp70/horseradish peroxidase-stained cells that demonstrated at least two or more processes (dendrites or axons) were counted. Mean numbers of HSP70 immunostained neurons were calculated for each animal. A one-way analysis of variance (ANOVA) was used to examine the effect of dose for each drug tested and a post hoc Schefe was used to test for differences at each dose compared to the controls for each drug. A two-way ANOVA was used to test for differences between different doses of the different drugs followed by a post hoc Schefe.

\section{RESULTS}

\section{MK-801 Behavioral Effects}

The i.p. injection of MK-801 (decreased NMDA receptor function) produces behavioral changes including a marked increase of motor activity and head weaving that have been reported and studied in detail previously (Brosnan-Watters
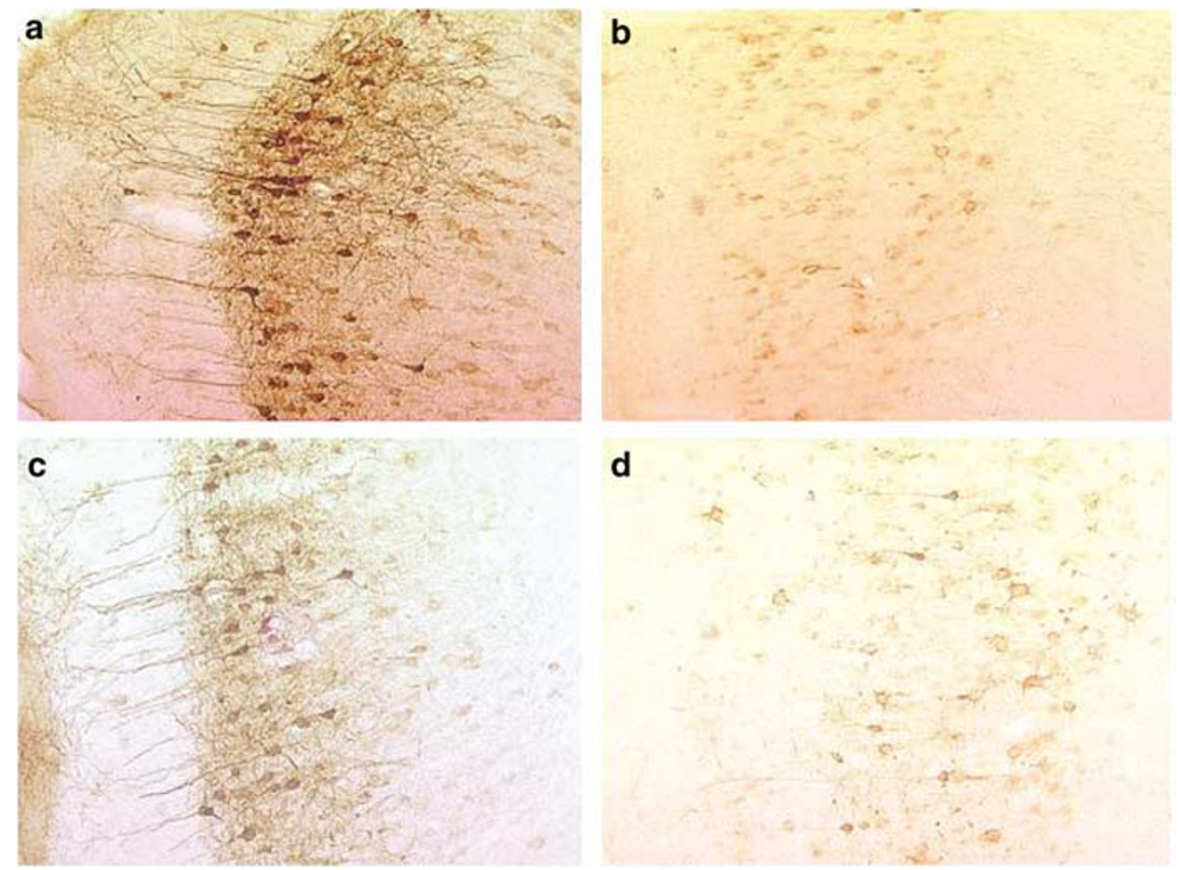

Figure I Hsp70 immunostaining of retrosplenial cortex neurons in adult rats $24 \mathrm{~h}$ following intraperitoneal MK-80 I ( I mg/kg) (a-d). At I h prior to the MK-80I animals received either intraperitoneal vehicle (a), clozapine $(10 \mathrm{mg} / \mathrm{kg})(\mathrm{b})$, ziprasidone (I mg/ $/ \mathrm{kg})(\mathrm{c})$, or ziprasidone (40 mg/kg) (d). 

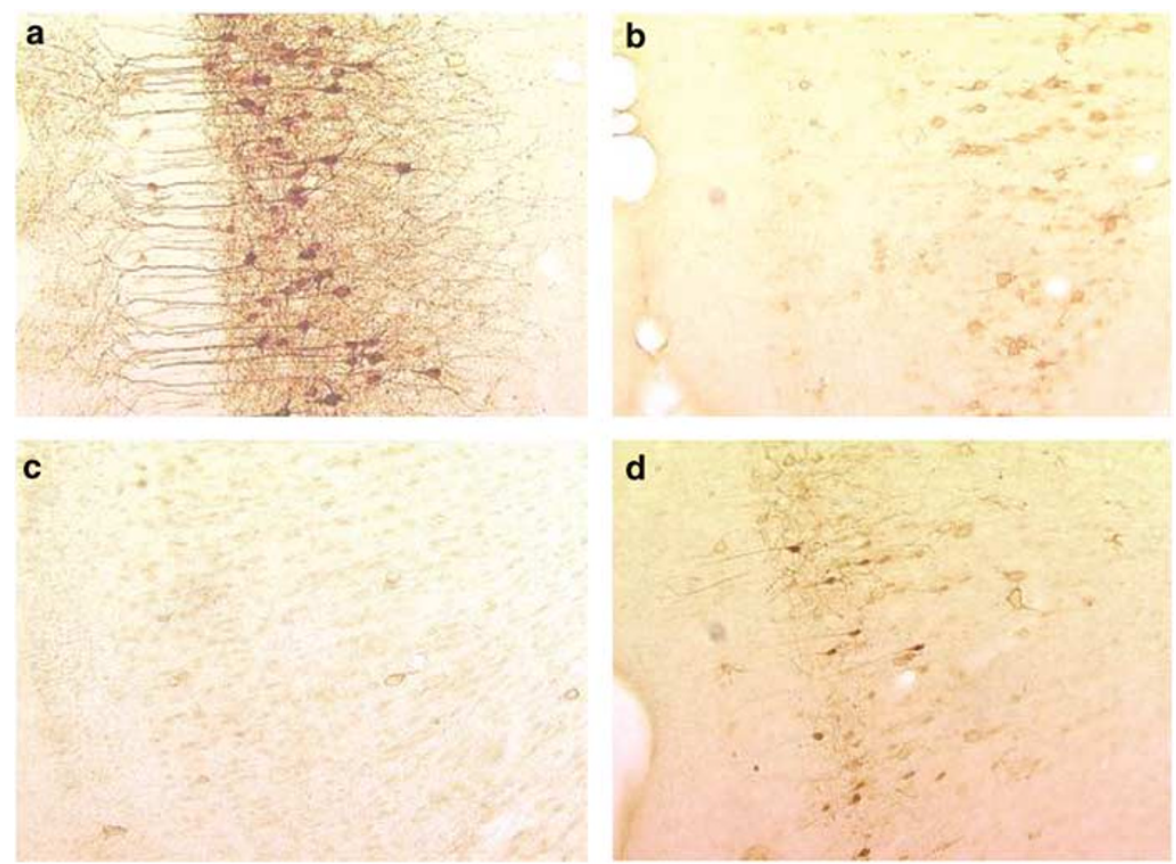

Figure $2 \mathrm{Hsp} 70$ immunostaining of retrosplenial cortex neurons in adult rats $24 \mathrm{~h}$ following intraperitoneal MK-80 $(\mathrm{I} \mathrm{mg} / \mathrm{kg})(\mathrm{a}-\mathrm{d})$. At $2 \mathrm{~h} \mathrm{prior}$ to the MK-80 I animals received either vehicle by gastric intubation (a), risperidone (I0 mg/kg) (b), olanzapine (20 mg/kg) (c), or quetiapine (60 mg/kg) (d).

et al, 1996, 1999; Mohn et al, 1999). The high dose of $1 \mathrm{mg} /$ $\mathrm{kg}$ of MK-801 in our studies produced similar behavioral effects that were more pronounced in some animals compared to others. Although we did not quantify the behavior, the prior administration of clozapine $(10 \mathrm{mg} / \mathrm{kg}$ i.p.) or ziprasidone $(40 \mathrm{mg} / \mathrm{kg}$ i.p.) completely abolished the hyperactivity produced by MK-801. The prior administration of quetiapine $(60 \mathrm{mg} / \mathrm{kg}$ g.i.), olanzapine $(20 \mathrm{mg} / \mathrm{kg}$ g.i.), or risperidone $(10 \mathrm{mg} / \mathrm{kg}$ g.i.) also decreased the hyperactivity produced by MK-801. These observations agree with better quantitative studies showing that atypical antipsychotics including clozapine, quetiapine, olanzapine, risperidone, and ziprasidone prevent the hyperactivity and other behavioral effects of NMDA antagonists like MK-801 and PCP (Cartmell et al, 2000; Sams-Dodd, 1997; AbdulMonim et al, 2003). When PP1 was given $1 \mathrm{~h}$ prior to the administration of $\mathrm{MK}-801$, the hyperactivity and head weaving was markedly attenuated, while PP3 (inactive structural analogue of PP1) injections produced no changes in behavior. Since this study was not designed to rigorously assess these behaviors, these observations will need to be confirmed quantitatively in future studies.

\section{Control Injections and MK-801 Induction of Hsp70 Protein in Neurons in Cortex}

I.p. administration of MK-801 at a dose of $1 \mathrm{mg} / \mathrm{kg}$ induced Hsp70 protein in large numbers of neurons in retrosplenial cortex $24 \mathrm{~h}$ later (Figures $1 \mathrm{a}$ and 2a). The Hsp70 was induced mainly in pyramidal neurons in layer 3 of retrosplenial cortex. Hsp70 protein was expressed in the perikarya of the pyramidal neurons and in the dendrites and axons of these neurons. Although not shown, the Hsp70-stained neurons extended from the most rostral to the most caudal portions of the retrosplenial cortex as defined by the rat brain atlas of Paxinos and Watson (third edition) and as described in previous studies (Sharp et al, 1991, 1992). Although there is some variability in the injury observed from experiment to experiment, the average number of Hsp70 immunostained neurons $/ 0.1 \mathrm{~mm}^{2}$ in retrosplenial cortex in the three separate experiments reported here (i.p., g.i., PP1) varied from $22 \pm 5$ (Figures 3 and 4 ) and $24 \pm 6$ (Figure 8) for animals given MK-801 plus DMSO vehicle up to $30 \pm 6$ neurons $/ 0.1 \mathrm{~mm}^{2}$ (Figures $5-7$ ) for animals given MK-801 plus systemic vehicle (water given through g.i.). The differences between these counts were significantly different $(p<0.05$, ANOVA followed by post-hoc Schefe) suggesting the DMSO vehicle decreased cell counts compared to water vehicle. A possible explanation for this effect is discussed below.

\section{Systemic Injections of Atypical Antispychotics Clozapine and Ziprasidone}

Systemic injections of clozapine one hour prior to MK-801 markedly decreased the number of Hsp70-labeled neurons in retrosplenial cortex (Figure 1b) when compared to vehicle injections prior to MK-801 (Figure 1a). There were virtually no pyramidal neurons labeled when clozapine was injected prior to MK-801. There were scattered Hsp70labeled neurons mainly in layer 3 that have a multipolar morphology most consistent with interneurons. Thus clozapine markedly decreased the numbers of Hsp70stained pyramidal neurons, and moderately decreased the numbers of stained neurons of the multipolar phenotype. Quantification of the numbers of Hsp70-labeled neurons/ $0.1 \mathrm{~mm}^{2}$ showed $22 \pm 5$ (mean $\pm \mathrm{SD}$ ) neurons following MK-801 and vehicle treatment, as compared to $5 \pm 4$ 
Control vs Clozapine

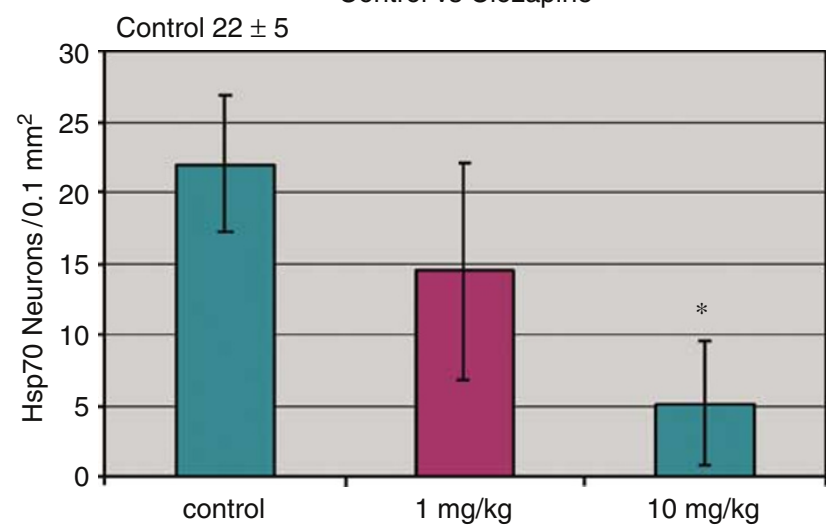

Figure 3 Systemic clozapine blocks injury to retrosplenial cortex caused by systemic MK-80 I. MK-80 I (I mg/kg) was administered intraperitoneally I h after injection of vehicle (left bar) or clozapine (I mg/ $/ \mathrm{kg}$-middle bar $n=6,10 \mathrm{mg} / \mathrm{kg}$-right bar $n=9)$. Animals were allowed to survive $24 \mathrm{~h}$ at which time Hsp70 immunostaining was performed. Data are presented as mean number of Hsp70-stained neurons $( \pm S E M) / 0.1 \mathrm{~mm}^{2}$ within the retrosplenial cortices. The controls $(n=8$, left bar) were injected with the vehicle used to dissolve the clozapine. ${ }^{*} p<0.05$ using ANOVA followed by post hoc Schefe compared to control.

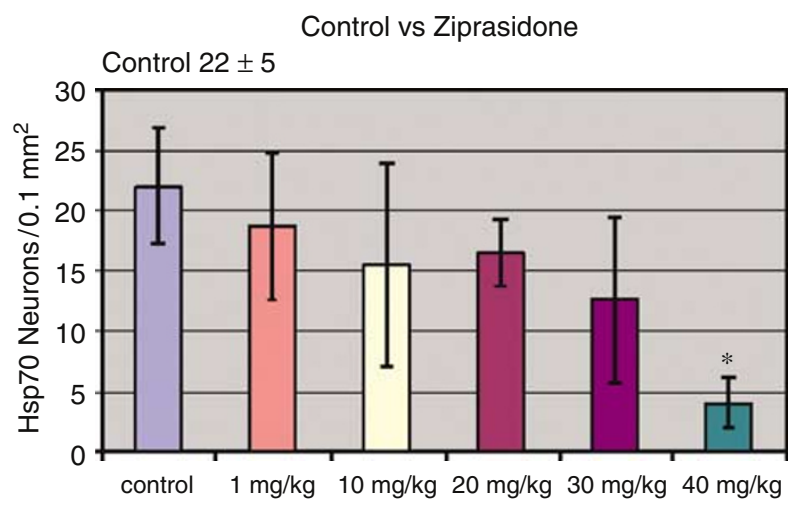

Figure 4 Systemic ziprasidone blocks injury to retrosplenial cortex caused by systemic MK-80l. MK-80 I ( $\mathrm{mg} / \mathrm{kg})$ was administered intraperitoneally I $\mathrm{h}$ after injection of I $\mathrm{mg} / \mathrm{kg}$ ziprasidone $(n=6), 10 \mathrm{mg} /$ $\mathrm{kg}$ ziprasidone $(n=9), 20 \mathrm{mg} / \mathrm{kg}$ ziprasidone $(n=6), 30 \mathrm{mg} / \mathrm{kg}$ ziprasidone $(n=6)$, or $40 \mathrm{mg} / \mathrm{kg}$ ziprasidone (right bar, $n=6$ ). Animals were allowed to survive $24 \mathrm{~h}$ at which time $\mathrm{Hsp} 70$ immunostaining was performed. Data are presented as mean number of Hsp70-stained neurons ( \pm SEM) $/ 0.1 \mathrm{~mm}^{2}$ within the retrosplenial cortices. The controls ( $n=8$, left bar) were injected with the vehicle used to dissolve the ziprasidone. ${ }^{*} p<0.05$ using ANOVA followed by post hoc Schefe compared to control.

(mean \pm SD) neurons following MK-801 plus $10 \mathrm{mg} / \mathrm{kg}$ clozapine (Figure 3$)(p<0.001)$. Although clozapine substantially decreased the numbers of Hsp70-labeled cells, the drug did not completely block neuronal labeling when given systemically at this dose. Lower doses of clozapine $(1 \mathrm{mg} /$ $\mathrm{kg}$ ) had no significant effect $(n=14 \pm 8$ for clozapine $1 \mathrm{mg} /$ $\mathrm{kg}$ ). The $10 \mathrm{mg} / \mathrm{kg}$ dose of clozapine decreased the number of labeled cells significantly when compared to the $1 \mathrm{mg} / \mathrm{kg}$ dose (Figure 3) $(p<0.05)$. Different delays between the administration of the clozapine and the administration of MK-801 might have increased or decreased the injury but

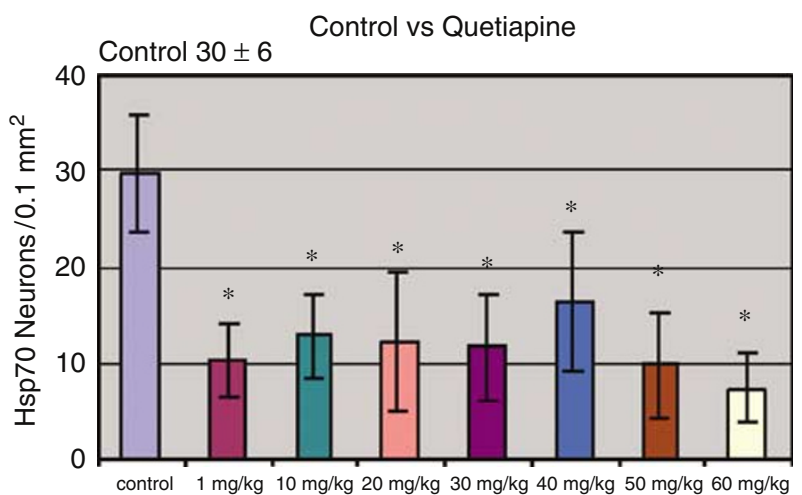

Figure 5 Systemic quetiapine blocks injury to retrosplenial cortex caused by systemic MK-80I. MK-80I (I mg/kg) was administered intraperitoneally $2 \mathrm{~h}$ after administration of vehicle (left bar), I mg/kg quetiapine $(n=6), 10 \mathrm{mg} / \mathrm{kg}$ quetiapine $(n=8), 20 \mathrm{mg} / \mathrm{kg}$ quetiapine $(n=7), 30 \mathrm{mg} / \mathrm{kg}$ quetiapine $(n=6), 40 \mathrm{mg} / \mathrm{kg}$ quetiapine $(n=6), 50 \mathrm{mg} /$ $\mathrm{kg}$ quetiapine $(n=6)$, or $60 \mathrm{mg} / \mathrm{kg}$ quetiapine $(n=8)$. Animals were allowed to survive $24 \mathrm{~h}$ at which time $\mathrm{Hsp} 70$ immunostaining was performed. Data are presented as mean number of Hsp70-stained neurons $( \pm$ SEM $) / 0.1 \mathrm{~mm}^{2}$ within the retrosplenial cortices. The controls $(n=7$, left bar) were administered $400 \mu$ of water by gastric intubation. *p $<0.05$ using ANOVA followed by post hoc Schefe compared to control.

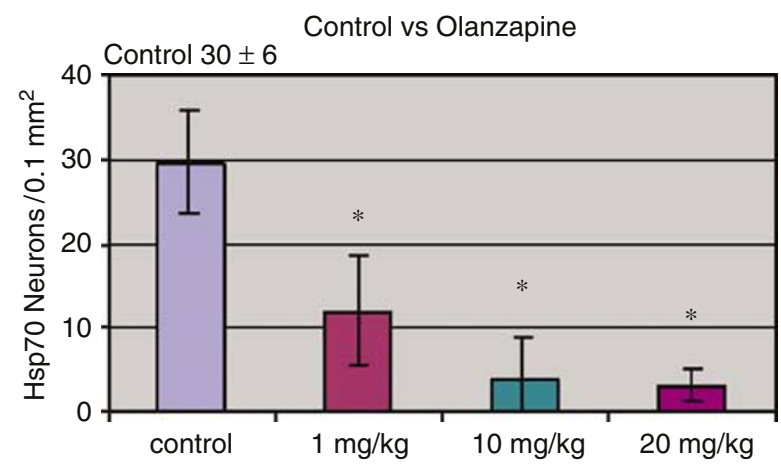

Figure $\mathbf{6}$ Systemic olanzapine blocks injury to retrosplenial cortex caused by systemic MK-80I. MK-80I (I mg/kg) was administered intraperitoneally $2 \mathrm{~h}$ after administration of vehicle (left bar), I mg/kg olanzapine (left-center bar, $n=7$ ), $10 \mathrm{mg} / \mathrm{kg}$ olanzapine (right center bar, $n=6$ ), or $20 \mathrm{mg} / \mathrm{kg}$ olanzapine (right bar, $n=6$ ). Animals were allowed to survive $24 \mathrm{~h}$ at which time $\mathrm{Hsp} 70$ immunostaining was performed. Data are presented as mean number of Hsp70-stained neurons $\left( \pm\right.$ SEM) $/ 0.1 \mathrm{~mm}^{2}$ within the retrosplenial cortices. The controls $(n=7$, left bar) were administered $400 \mu$ l of water by gastric intubation. $* p<0.05$ using ANOVA followed by post hoc Schefe compared to control.

this variable was not explored since a large effect was obtained using the 1-h time interval.

Systemic injections of ziprasidone $(40 \mathrm{mg} / \mathrm{kg}$; Figure $1 \mathrm{~d})$ $1 \mathrm{~h}$ prior to MK-801 markedly decreased the numbers of Hsp70-labeled neurons $/ 0.1 \mathrm{~mm}^{2}$ in retrosplenial cortex when to compared control animals followed by MK-801 (Figure 1a). Again there were virtually no pyramidal neurons labeled when high-dose ziprasidone $(40 \mathrm{mg} / \mathrm{kg})$ was injected prior to MK-801, and the morphology of the remaining labeled cells had multipolar morphology most consistent with interneurons (Figure 1d). Quantification of the numbers of Hsp70-labeled neurons $/ 0.1 \mathrm{~mm}^{2}$ showed 


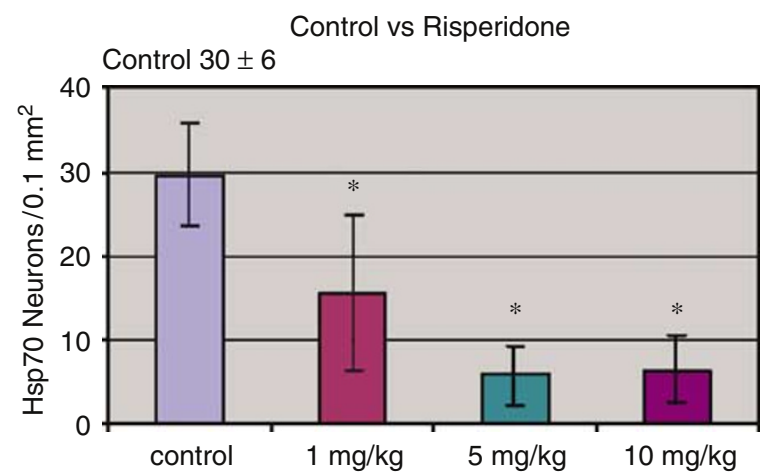

Figure 7 Systemic risperidone blocks injury to retrosplenial cortex caused by systemic MK-80I. MK-80I (I mg/ $/ \mathrm{kg}$ ) was administered intraperitoneally $2 \mathrm{~h}$ after administration of vehicle (left bar), I $\mathrm{mg} / \mathrm{kg}$ risperidone (left center bar, $n=6$ ), $5 \mathrm{mg} / \mathrm{kg}$ risperidone (right center, $n=7$ ), or $10 \mathrm{mg} / \mathrm{kg}$ risperidone (right bar, $n=8$ ). Animals were allowed to survive $24 \mathrm{~h}$ at which time $\mathrm{Hsp} 70$ immunostaining was performed. Data are presented as mean number of Hsp70-stained neurons ( \pm SEM) $/ 0.1 \mathrm{~mm}^{2}$ within the retrosplenial cortices. The controls $(n=7$, left bar) were administered $400 \mu$ l of water by gastric intubation. ${ }^{*} p<0.05$ using ANOVA followed by post hoc Schefe compared to control.

$22 \pm 5$ for control animals injected with vehicle and $4 \pm 2$ labeled neurons for animals receiving a $40 \mathrm{mg} / \mathrm{kg}$ dose of ziprasidone followed by MK-801 (Figure 4). The $40 \mathrm{mg} / \mathrm{kg}$ dose significantly reduced the number of stained neurons compared to vehicle control (Figure 4) $(p<0.01)$. Other doses of ziprasidone were quantified and showed $19 \pm 6$ Hsp70-labeled neurons $/ 0.1 \mathrm{~mm}^{2}$ for animals receiving $1 \mathrm{mg} /$ $\mathrm{kg}, 16 \pm 8$ neurons for animals receiving $10 \mathrm{mg} / \mathrm{kg}, 17 \pm 3$ neurons for animals receiving $20 \mathrm{mg} / \mathrm{kg}$, and $13 \pm 7$ neurons for animals receiving $30 \mathrm{mg} / \mathrm{kg}$. None of those doses were statistically significantly different from the vehicle control. When the other doses were compared to the $40 \mathrm{mg} / \mathrm{kg}$ dose, the 1,10 , and $20 \mathrm{mg} / \mathrm{kg}$ had significantly more labeled neurons (Figure 4) $(p<0.05)$.

\section{Systemic Administration of Quetiapine, Olanzapine, and Risperidone by g.i.}

Systemic administration of atypical antipsychotics (Figure $2 \mathrm{~b}-\mathrm{d}) 2 \mathrm{~h}$ prior to MK- 801 markedly decreased the number of Hsp70-labeled neurons in retrosplenial cortex when compared to systemic administration of vehicle (Figure 2a). There were virtually no pyramidal neurons labeled when the animal was pretreated with risperidone (Figure $2 \mathrm{~b}$ ) or olanzapine (Figure 2c), and relatively few pyramidal neurons when animals were injected with quetiapine (Figure 2d). Most of the remaining, poorly stained neurons following pretreatment with atypical antipsychotics had a morphology that was most consistent with multipolar interneurons (Figure 2b).

Quantification of the numbers of Hsp70-labeled neurons/ $0.1 \mathrm{~mm}^{2}$ showed $30 \pm 6$ (mean $\pm \mathrm{SD}$ ) neurons on each section following MK-801 and vehicle treatment. Following quetiapine, quantification of the Hsp70-labeled neurons/ $0.1 \mathrm{~mm}^{2}$ showed $10 \pm 4$ cells for the $1 \mathrm{mg} / \mathrm{kg}$ dose, $13 \pm 4$ for the $10 \mathrm{mg} / \mathrm{kg}$ dose, $12 \pm 7$ for the $20 \mathrm{mg} / \mathrm{kg}$ dose, $12 \pm 6$ for the $30 \mathrm{mg} / \mathrm{kg}$ dose, $16 \pm 7$ for the $40 \mathrm{mg} / \mathrm{kg}$ dose, $10 \pm 6$ for the $50 \mathrm{mg} / \mathrm{kg}$ dose, and $7 \pm 3$ for the $60 \mathrm{mg} / \mathrm{kg}$ dose
(Figure 5). All seven of the different doses showed significant decreases in the neuronal labeling when given $2 \mathrm{~h}$ before injections of MK-801 when compared to vehicle (Figure 5) $(p<0.05)$. No dose $(1-60 \mathrm{mg} / \mathrm{kg})$ was statistically different from the other.

Following olanzapine, quantification of the Hsp70-labeled neurons $/ 0.1 \mathrm{~mm}^{2}$ showed $12 \pm 7$ for the $1 \mathrm{mg} / \mathrm{kg}$ dose, $4 \pm 5$ for the $10 \mathrm{mg} / \mathrm{kg}$ dose, and $3 \pm 2$ for the $20 \mathrm{mg} / \mathrm{kg}$ dose (Figure 6). All of these doses showed significant decreases in labeled neurons when compared to the vehicle treatment (Figure 6) $(p<0.001)$. Again the doses were not significantly different from each other. Following risperidone, quantification of the Hsp70-labeled neurons $/ 0.1 \mathrm{~mm}^{2}$ showed $16 \pm 9$ for the $1 \mathrm{mg} / \mathrm{kg}$ dose, $6 \pm 4$ for the $5 \mathrm{mg} / \mathrm{kg}$ dose, and $6 \pm 4$ for the $10 \mathrm{mg} / \mathrm{kg}$ dose (Figure 7). All of the doses decreased the number of labeled neurons significantly when compared to the vehicle treatment (Figure 7) $(p<0.01$ for $1 \mathrm{mg} / \mathrm{kg}$ dose, $p<0.001$ for the 5 and $10 \mathrm{mg} / \mathrm{kg}$ doses). The doses were not statistically different from each other.

\section{Comparison of Similar Doses of Atypical Antipsychotics to Determine the Effectiveness of the Antipsychotics}

Statistical analysis was used to compare the effectiveness of the drugs $v s$ each other. A two way ANOVA was performed followed by Schefe post hoc tests. The data from all of the $1 \mathrm{mg} / \mathrm{kg}$ doses for each of the drugs were used and showed no significant differences. When the $10 \mathrm{mg} / \mathrm{kg}$ doses were compared between the different drugs, there were some statistically significant differences. Risperidone, olanzapine, and clozapine had fewer stained neurons when compared to quetiapine $(p<0.05)$ and possibly when compared to ziprasidone $(p<0.07)$ at the $10 \mathrm{mg} / \mathrm{kg}$ doses of each.

\section{Systemic Injections of Src Inhibitor PP1 and the PP1 Analog, PP3}

Systemic injections of PP1 $1 \mathrm{~h}$ prior to MK-801 markedly decreased the number of Hsp70-labeled neurons $/ 0.1 \mathrm{~mm}^{2}$ in retrosplenial cortex when compared vehicle injections prior to MK-801 (not shown). Quantification of the numbers of labeled neurons showed $24 \pm 6$ (mean \pm SEM) neurons on each section following MK-801 and vehicle treatment, as compared to $10 \pm 3$ (mean \pm SEM) neurons following MK801 plus $0.1 \mathrm{mg} / \mathrm{kg}$ PP1, $13 \pm 5$ neurons following MK-801 plus $1 \mathrm{mg} / \mathrm{kg} \mathrm{PP1}$, and $11 \pm 4$ neurons following MK-801 plus $10 \mathrm{mg} / \mathrm{kg}$ PP1 $(p<0.05$ for each dose compared to control) (Figure 8). Although PP1 substantially decreased the numbers of Hsp70-labeled cells, the drug did not completely block neuronal labeling when given systemically at these doses. Different delays between the administration of the PP1 and the administration of MK-801 might have increased or decreased the injury, but this variable was not explored since a large effect was obtained using the 1-h time interval at the $0.1 \mathrm{mg} / \mathrm{kg}$ dose.

The nonfunctional analog of PP1 (PP3) was administered to animals to ensure the specificity of PP1. Systemic injections of PP3 $(0.1,1$, and $10 \mathrm{mg} / \mathrm{kg}) 1 \mathrm{~h}$ prior to MK801 had no significant effect on the numbers of Hsp70labeled neurons in retrosplenial cortex when compared with vehicle (not shown). Quantification of the numbers of 


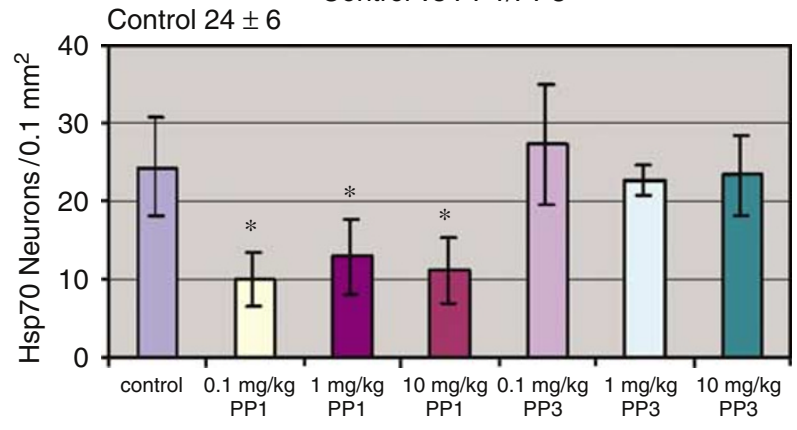

Figure 8 Systemic Src antagonist (PPI) but not a PPI analogue (PP3) blocks injury to retrosplenial cortex caused by systemic MK-80 I. MK-80 I $(\mathrm{I} \mathrm{mg} / \mathrm{kg})$ was administered intraperitoneally $\mathrm{I} h$ after injection of vehicle (left bar) or PPI $(0.1 \mathrm{mg} / \mathrm{kg}, n=7),(1 \mathrm{mg} / \mathrm{kg}, n=7),(10 \mathrm{mg} / \mathrm{kg}, n=7)$ or PP3 $(0.1 \mathrm{mg} / \mathrm{kg}, n=7),(1 \mathrm{mg} / \mathrm{kg} . n=6),(10 \mathrm{mg} / \mathrm{kg} n=7)$. Animals were allowed to survive $24 \mathrm{~h}$ at which time Hsp70 immunostaining was performed. Data are presented as mean number of Hsp70-stained neurons $\left( \pm\right.$ SEM $/ 0.1 \mathrm{~mm}^{2}$ within the retrosplenial cortices. The controls ( $n=7$, left bar) were injected with the vehicle used to solubilize PPI and PP3. *p $<0.05$ using ANOVA followed by post hoc Schefe compared to control.

labeled neurons showed $24 \pm 6$ neurons for animals receiving vehicle followed by MK- 801 , as compared to $27 \pm 8$ labeled neurons for animals receiving a $0.1 \mathrm{mg} / \mathrm{kg}$ dose of PP3 followed by MK-801, 23 \pm 2 labeled neurons for animals receiving a $1 \mathrm{mg} / \mathrm{kg}$ dose of PP3 prior to MK-801 administration, and $23 \pm 5$ labeled neurons for animals receiving a $10 \mathrm{mg} / \mathrm{kg}$ dose of PP3. None of the PP3 doses were statistically significantly different from each other or from the control (Figure 8).

\section{Relative Potency of All Drugs Tested}

Based upon the dose-responses shown in Figures 3-8, third-order curves were derived to describe the effects of dose on neuronal injury. Using the equations for these curves, the ED50 was calculated for each drug, that is the dose that decreased the number of Hsp70-stained neurons/ $0.1 \mathrm{~mm}^{2}$ by $50 \%$ compared to control. This approach did not work well for PP1 because it displayed an atypical response compared to the other drugs tested though the ED50 for PP1 appears to be less than $0.1 \mathrm{mg} / \mathrm{kg}$ (Figure 8). The ED50s for decreasing injury due to MK-801 $(1 \mathrm{mg} / \mathrm{kg})$ were as follows: PP1 $<0.1 \mathrm{mg} / \mathrm{kg}$; olanzapine $0.8 \mathrm{mg} / \mathrm{kg}$; risperidone $1 \mathrm{mg} / \mathrm{kg}$; clozapine $3 \mathrm{mg} / \mathrm{kg}$; ziprasidone $32 \mathrm{mg} /$ $\mathrm{kg}$; and quetiapine $45 \mathrm{mg} / \mathrm{kg}$.

\section{DISCUSSION}

The results show that all of the atypical antipsychotics tested, along with a Src antagonist, decreased the injury to rat retrosplenial cortex produced by the noncompetitive NMDA receptor antagonist, MK-801. The most potent atypical antipsychotic drugs were olanzapine, risperidone, and clozapine with ziprasidone and quetiapine being an order of magnitude less potent. This potency profile is similar to that observed in the treatment of humans with psychosis (Leo and Regno, 2000; Miyamoto et al, 2005; Sprague et al, 2004). This animal data must be considered with caution since only a few atypical antipsychotics were tested, a variety of drugs block injury produced by MK-801, and both oral and i.p. routes of drug administration are used in our animal studies. The finding that a novel compound, the Src antagonist PP1, is the most compound tested for decreasing the injury produced by MK-801 in this rodent animal model might suggest a role for Src kinases in mediating PCP and ketamine (Special K) induced behaviors in people.

The data confirm the findings of several previous animal studies. The typical antipsychotic haloperidol was first shown to block the cortical injury produced by noncompetitive NMDA antagonists including PCP, ketamine and MK-801 (Sharp et al, 1992). Haloperidol blocks formation of vacuoles in pyramidal neurons in retrosplenial cortex (ED50-5 mg/kg) (Farber et al, 1996) and haloperidol also blocks Hsp70 induction in the pyramidal neurons following PCP (ED50-0.9 mg/kg; Sharp et al, 1994a, b) and ketamine (ED50-0.1 mg/kg; Nakki et al, 1996).

Some of the atypical antipsychotics have also been shown to block injury produced by the noncompetitive antagonists. Clozapine blocks Hsp70 induction in pyramidal neurons produced by PCP (ED50-1 mg/kg; Sharp et al, $1994 b)$. Moreover, clozapine (ED50-2.8 mg/kg), olanzapine (ED50-0.6 mg/kg), and fluperlapine (ED50-2.4 mg/ $\mathrm{kg}$ ) block formation of vacuoles in pyramidal neurons in retrosplenial cortex produced by systemic MK-801 (0.5 mg/ kg) (Farber et al, 1993, 1996; Olney and Farber, 1994). These studies are consistent with the present study that shows that olanzapine and risperidone are slightly more potent than clozapine at decreasing MK-801-mediated injury, and that ziprasidone and quetiapine are an order of magnitude less potent at preventing the injury in rat retrosplenial cortex (current study).

The potency of these atypical antipsychotics at preventing injury to rat retrosplenial cortex is roughly similar to the potency of the drugs in treating psychosis in humans. Although doses vary, the average doses of the atypicals used to treat psychosis in humans are as follows: risperidone, 4$8 \mathrm{mg} /$ day; olanzapine $5-20 \mathrm{mg} /$ day; clozapine $6.25-400 \mathrm{mg} /$ day; ziprasidone $40-160 \mathrm{mg} / \mathrm{day}$; and quetiapine $130-$ $800 \mathrm{mg} /$ day (Leo and Regno, 2000; Miyamoto et al, 2005; Sprague et al, 2004). This potency profile compares roughly to the potency in the present study of olanzapine $>$ risperidone $>$ clozapine $>$ ziprasidone $>$ quetiapine. The comparisons of the rodent and human data are complicated by (1) both oral and i.p. routes being used in the rats that confound dose comparisons (2) the role of side effects in determining dosing in humans (3) and inherent differences in anatomy and pharmacology of the rodent and human brains. However, even though clozapine and ziprasidone were given i.p., they were among the less potent drugs that blocked injury produced by MK-801, suggesting that the route of administration did not have major effects on the potency profiles.

Another variable in the study was that DMSO and water were both used as vehicles. It was notable that the DMSOtreated controls had fewer Hsp70-stained neurons in retrosplenial cortex compared to the water-treated controls (see results). This may have occurred because DMSO is a 
modest antioxidant that can protect against stroke and other types of brain injury (Shimizu et al, 1997). In addition, we have previously shown that another antioxidant 1,3-dimethylthiourea markedly protects against the neuronal injury produced by systemic MK-801 (Rajdev et al, 1998). It is notable that glutathione and other antioxidants are reported to be low in various tissues including brain of schizophrenic subjects (Castagne et al, 2004; Do et al, 2000).

The atypical antipsychotics not only block the injury produced by noncompetitive NMDA receptor antagonists, they also produce other effects that are relevant to the mechanisms of action of these drugs. NMDA receptor antagonists, including ketamine, PCP and MK-801, produce abnormalities of glucose metabolism in brain including limbic cortex and thalamus of rodents (Hammer and Herkenham, 1983; Duncan et al, 2000, 2003) and man (Buchsbaum et al, 1996; Gao et al, 1993; Tamminga, 1999). Antipsychotics modulate these metabolic alterations, which are thought to be due to increased neuronal activity. Clozapine and olanzapine block ketamine-induced hypermetabolism, whereas risperidone and haloperidol do not (Duncan et al, 1999, 2000, 2003). Thus, the ability of drugs to block hypermetabolism produced by NMDA antagonists cannot be used to screen for antipsychotics, though these studies certainly point to different modes of actions of the drugs (Duncan et al, 2003). In addition, most typical and atypical antipsychotics block the hyperactivity and many other behavioral abnormalities produced by noncompetitive NMDA receptor antagonists (Cartmell et al, 2000; Sams-Dodd, 1997; Abdul-Monim et al, 2003). Finally, a series of studies have shown that prepulse inhibition (PPI), which is reduced in patients with schizophrenia, is also reduced by $\mathrm{PCP}$ and other NMDA antagonists, and that the reduction of PPI produced by NMDA antagonists can be reversed by treatment with clozapine and other atypical antipsychotics (Bakshi and Geyer, 1995, 1998; Geyer et al, 2001; Swerdlow et al, 1998). Although microglial proliferation/activation can occur in schizophrenic brain (Radewicz et al, 2000), and microglial proliferation/activation occurs following NMDA antagonist toxicity that is blocked by antioxidants but not by haloperidol (Nakki et al, 1996; Rajdev et al, 1998), it is not known if atypical antipsychotics or Src antagonists would block microglial proliferation or activation.

Although typical and atypical antipsychotic actions on D2 receptors may decrease psychosis, the unique properties of atypical antipsychotic drugs may be explained by their effects on other receptors including other dopamine (D1, D3, D4), serotonin (5-HT2A, 5-HT1A, 5-HT3,6, and 7 receptors) and alpha-1 adrenergic receptors (Miyamoto et al, 2005; Richelson, 1999; Tatsumi et al, 1999). The actions on non-D2 receptors are thought to account for their effects on the negative symptoms of schizophrenia (Leo and Regno, 2000; Miyamoto et al, 2005; Sprague et al, 2004).

Animal studies using the MK-801 injury model used here have identified regions, circuits and receptors that interact to produce injury in limbic cortex via activation of thalamus and basal forebrain (Tomitaka et al, 2000b; Sharp et al, 2001; Farber et al, 2002, 2003). Although the current study does not address mechanisms and sites of action of the atypical antipsychotic drugs, it is likely the atypical antipsychotics protect retrosplenial cortex by blocking dopamine D2 and other receptors associated with thalamic, midbrain, and basal forebrain projections to limbic cortex (Farber et al, 2003; Sharp et al, 2001).

There are a number of reasons to suggest Src biology could be relevant to the injury produced by NMDA antagonists in rodents. Src is a family of nonreceptor, tyrosine kinases (SFKs, Src-family kinases) that bind to the NMDA receptor including the PSD95 postsynaptic protein, and phosphorylate the NR2A and NR2B subunits of the receptor to modulate NMDA receptor function and plasticity (Salter and Kalia, 2004). SFKs can be modulated by tyrosine phosphatases, G-protein-coupled receptors, receptor protein tyrosine kinase signaling, the Ras pathway, and the cytokine receptor and integrin pathways. Many of the physiological actions of NMDA receptors are critically dependent upon SFKs (Gingrich et al, 2004; Hayashi and Huganir, 2004; Kalia and Salter, 2003; Lu et al, 1999). As an example, SFKs are necessary for the induction of long-term potentiation in the CA1 region of hippocampus (Salter and Kalia, 2004).

Therefore, it would not be surprising if Src-tyrosine kinases might be involved in the signaling that occurs when NMDA receptors are blocked by noncompetitive NMDA receptor antagonists. Indeed, MK-801 and PCP increase Src mRNA in brain (Linden et al, 2001). MK-801 increased Src protein and enzyme activity levels, and MK-801 increased tyrosine phosphorylation of the NMDA receptor subunit NR2A (Linden et al, 2001). These results provide evidence for the contribution of Src and tyrosine phosphorylation of NMDA receptors in the pharmacological actions of noncompetitive NMDA receptor antagonists. The current results also support this conclusion. Our data suggest that the neuronal injury in retrosplenial cortex of adult rats produced by noncompetitive NMDA receptor antagonists is mediated by Src-tyrosine kinases, and that this NMDA receptor blockade and Src-mediated cell injury can be blocked by inhibiting Src-tyrosine kinases.

Although the Src antagonist most likely acts immediately downstream of the NMDA receptors being blocked by MK801 , other interpretations of the data should be considered. The atypical antipsychotics medications tested here likely prevent injury by blocking a variety of receptors including dopamine, serotonin, and adrenergic receptors. It is possible that the Src antagonist acts downstream of all of the same receptors. Although this may seem unlikely, it is also surprising that blocking downstream effects of the NMDA receptor actually prevents injury as well. It is conceivable that NMDA receptor blockade facilitates the actions of glutamate on other glutamate receptors or facilitates other glutamate receptors as suggested by Tamminga (1999). Src antagonists could also act following displacement of MK-801 from the NMDA receptors (Tamminga, 1999). Thus, the Src antagonist could act downstream of other glutamate receptors like the metabotropic receptors that also modulate injury produced by MK-801 (Carter et al, 2004).

The fact that noncompetitive NMDA receptor antagonists produce positive and negative features of the psychosis observed in humans has led to the NMDA receptorhypofunction hypothesis of schizophrenia (Krystal et al, 
1999b). This hypothesis stirred clinical trials of NMDA agonists to treat the symptoms of schizophrenia (Goff et al, 1999; Heresco-Levy et al, 1999). It is unclear from this study and the current literature, however, whether inhibiting downstream effects of NMDA receptors by Src kinase inhibitors and similar drugs will be useful pharmacological targets for the treatment of psychosis, hyperactivity and/or anxiety.

It is not clear why the Src antagonist, PP1, and the atypical antipsychotic, quetiapine, did not completely block MK-801-induced cortical injury. It is possible that these drugs do not block receptors or molecules that are blocked by haloperidol and the other drugs tested in this study. These observations could be relevant to treatment of humans, since there is increasing evidence that schizophrenia is a progressive disease with ongoing neuropathology that might be slowed or preventable using antipsychotics and other types of drugs (Christensen et al, 2004). Perhaps treatment with typical and atypical antipsychotics, antioxidants, and perhaps Src inhibitors that are best at blocking neuronal injury in the MK-801/PCP rodent model might be most useful for slowing neuropathological injury in schizophrenia and other human diseases associated with psychosis.

\section{ACKNOWLEDGEMENTS}

These studies were supported by NIMH-RO163079 to FRS. We thank the undergraduate and rotating graduate students at the University of Cincinnati who helped with the performance and analysis of some of these studies.

\section{REFERENCES}

Abdul-Monim Z, Reynolds GP, Neill JC (2003). The atypical antipsychotic ziprasidone, but not haloperidol, improves phencyclidine-induced cognitive deficits in a reversal learning task in the rat. J Psychopharmacol 17: 57-65.

Akiyama C, Yuguchi T, Nishio M, Tomishima T, Fujinaka T, Taniguchi $M$ et al (2004). Src family kinase inhibitor PP1 reduces secondary damage after spinal cord compression in rats. J Neurotrauma 7: 923-931.

Auer RN (1994). Assessing structural changes in the brain to evaluate neurotoxicological effects of NMDA receptor antagonists. Psychopharmacol Bull 30: 585-591.

Auer RN (1996). Effect of age and sex on $N$-methyl-D-aspartate antagonist-induced neuronal necrosis in rats. Stroke 27: 743-746.

Auer RN, Coulter KC (1994). The nature and time course of neuronal vacuolation induced by the $N$-methyl-D-aspartate antagonist MK-801. Acta Neuropathol (Berlin) 87: 1-7.

Bakshi VP, Geyer MA (1995). Antagonism of phencyclidineinduced deficits in prepulse inhibition by the putative atypical antipsychotic olanzapine. Psychopharmacology (Berlin) 122: 198-201.

Bakshi VP, Geyer MA (1998). Multiple limbic regions mediate the disruption of prepulse inhibition produced in rats by the noncompetitive NMDA antagonist dizocilpine. J Neurosci 18: 8394-8401.

Breier A, Malhotra AK, Pinals DA, Weisenfeld NI, Pickar D (1997). Association of ketamine-induced psychosis with focal activation of the prefrontal cortex in healthy volunteers. Am J Psychiatr 154: 805-811.
Brosnan-Watters G, Wozniak DF, Nardi A, Olney JW (1996). Acute behavioral effects of MK-801 in the mouse. Pharmacol Biochem Behav 53: 701-711.

Brosnan-Watters G, Wozniak DF, Nardi A, Olney JW (1999). Parallel recovery of MK-801-induced spatial learning impairment and neuronal injury in male mice. Pharmacol Biochem Behav 62: 111-122.

Buchsbaum MS, Someya T, Teng CY, Abel L, Chin S, Najafi A et al (1996). PET and MRI of the thalamus in never-medicated patients with schizophrenia. Am J Psychiatr 153: 191-199.

Carter K, Dickerson J, Schoepp DD, Reilly M, Herring N, Williams $\mathrm{J}$ et al (2004). The mGlu2/3 receptor agonist LY379268 injected into cortex or thalamus decreases neuronal injury in retrosplenial cortex produced by NMDA receptor antagonist MK-801: possible implications for psychosis. Neuropharmacology 47: $1135-1145$.

Cartmell J, Monn JA, Schoepp DD (2000). Attenuation of specific PCP-evoked behaviors by the potent mGlu2/3 receptor agonist, LY379268 and comparison with the atypical antipsychotic, clozapine. Psychopharmacology (Berlin) 148: 423-429.

Castagne V, Rougemont M, Cuenod M, Do KQ (2004). Low brain glutathione and ascorbic acid associated with dopamine uptake inhibition during rat's development induce long-term cognitive deficit: relevance to schizophrenia. Neurobiol Dis 15: 93-105.

Christensen J, Holcomb J, Garver DL (2004). State-related changes in cerebral white matter may underlie psychosis exacerbation. Psychiatr Res 15: 71-78.

Do KQ, Trabesinger AH, Kirsten-Kruger M, Lauer CJ, Dydak U, Hell D et al (2000). Schizophrenia: glutathione deficit in cerebrospinal fluid and prefrontal cortex in vivo. Europ $J$ Neurosci 12: 3721-3728.

Duncan GE, Miyamoto S, Leipzig JN, Lieberman JA (2000). Comparison of the effects of clozapine, risperidone, and olanzapine on ketamine-induced alterations in regional brain metabolism. J Pharmacol Exp Ther 293: 8-14.

Duncan GE, Miyamoto S, Lieberman JA (2003). Chronic administration of haloperidol and olanzapine attenuates ketamineinduced brain metabolic activation. J Pharmacol Exp Ther 305: 999-1005.

Duncan GE, Zorn S, Lieberman JA (1999). Mechanisms of typical and atypical antipsychotic drug action in relation to dopamine and NMDA receptor hypofunction hypotheses of schizophrenia. Mol Psychiatr 4: 418-428.

Farber NB, Foster J, Duhan NL, Olney JW (1996). Olanzapine and fluperlapine mimic clozapine in preventing MK-801 neurotoxicity. Schizophr Res 21: 33-37.

Farber NB, Jiang X, Dikranian K, Nemmers B (2003). Muscimol prevents NMDA antagonist neurotoxicity by activating GABAA receptors in several brain regions. Brain Res 993: 90-100.

Farber NB, Kim SH, Dikranian K, Jiang XP, Heinkel C (2002). Receptor mechanisms and circuitry underlying NMDA antagonist neurotoxicity. Mol Psychiatr 7: 32-43.

Farber NB, Price MT, Labruyere J, Nemnich J, St Peter H, Wozniak DF et al (1993). Antipsychotic drugs block phencyclidine receptor-mediated neurotoxicity. Biol Psychiatr 34: 119-121.

Farber NB, Wozniak DF, Price MT, Labruyere J, Huss J, St Peter H et al (1995). Age-specific neurotoxicity in the rat associated with NMDA receptor blockade: potential relevance to schizophrenia? Biol Psychiatr 38: 788-796.

Gao XM, Shirakawa O, Du F, Tamminga CA (1993). Delayed regional metabolic actions of phencyclidine. Eur J Pharmacol 241: 7-15.

Geyer MA, Krebs-Thomson K, Braff DL, Swerdlow NR (2001). Pharmacological studies of prepulse inhibition models of sensorimotor gating deficits in schizophrenia: a decade in review. Psychopharmacology (Berlin) 156: 117-154.

Gingrich JR, Pelkey KA, Fam SR, Huang Y, Petralia RS, Wenthold $\mathrm{RJ}$ et al (2004). Unique domain anchoring of Src to synaptic 
NMDA receptors via the mitochondrial protein NADH dehydrogenase subunit 2. Proc Natl Acad Sci USA 101: 6237-6242.

Goff DC, Tsai G, Levitt J, Amico E (1999). A placebo-controlled trial of D-cycloserine added to conventional neuroleptics in patients with schizophrenia. Arch Gen Psychiatr 56: 21-27.

Hammer Jr RP, Herkenham M (1983). Altered metabolic activity in the cerebral cortex of rats exposed to ketamine. J Comp Neurol 220: 396-404.

Hayashi T, Huganir RL (2004). Tyrosine phosphorylation and regulation of the AMPA receptor by SRC family tyrosine kinases. J Neurosci 24: 6152-6160.

Heresco-Levy U, Javitt DC, Ermilov M, Mordel C, Silipo G, Lichtenstein M (1999). Efficacy of high-dose glycine in the treatment of enduring negative symptoms of schizophrenia. Arch Gen Psychiatr 56: 29-36.

Javitt DC, Zukin SR (1991). Recent advances in the phencyclidine model of schizophrenia. Am J Psychiatr 148: 1301-1308.

Kalia LV, Salter MW (2003). Interactions between Src family protein tyrosine kinases and PSD-95. Neuropharmacology 45: 720-728.

Krystal JH, D'Souza DC, Karper LP, Bennett A, Abi-Dargham A, Abi-Saab D et al (1999a). Interactive effects of subanesthetic ketamine and haloperidol in healthy humans. Psychopharmaco$\log y$ (Berlin) 145: 193-204.

Krystal JH, D'Souza DC, Petrakis IL, Belger A, Berman RM, Charney DS et al (1999b). NMDA agonists and antagonists as probes of glutamatergic dysfunction and pharmacotherapies in neuropsychiatric disorders. Harv Rev Psychiatr 7: 125-143.

Lahti AC, Holcomb HH, Medoff DR, Tamminga CA (1995). Ketamine activates psychosis and alters limbic blood flow in schizophrenia. Neuroreport 6: 869-872.

Leo RJ, Regno PD (2000). Atypical antipsychotic use in the treatment of psychosis in primary care. Prim Care Companion J Clin Psychiatr 2: 194-204.

Linden A, Storvik M, Lakso M, Haapasalo A, Lee D, Witkin JM et al (2001). Increased expression of neuronal Src and tyrosine phosphorylation of NMDA receptors in rat brain after systemic treatment with MK-801. Neuropharmacology 40: 469-481.

Lu WY, Xiong ZG, Lei S, Orser BA, Dudek E, Browning MD et al (1999). G-protein-coupled receptors act via protein kinase $C$ and Src to regulate NMDA receptors. Nat Neurosci 2: 331-338.

Malhotra AK, Pinals DA, Adler CM, Elman I, Clifton A, Pickar D et al (1997). Ketamine-induced exacerbation of psychotic symptoms and cognitive impairment in neuroleptic-free schizophrenics. Neuropsychopharmacology 17: 141-150.

Malhotra AK, Pinals DA, Weingartner H, Sirocco K, Missar CD, Pickar D et al (1996). NMDA receptor function and human cognition: the effects of ketamine in healthy volunteers. Neuropsychopharmacology 14: 301-307.

Miyamoto S, Duncan GE, Marx CE, Lieberman JA (2005). Treatments for schizophrenia: a critical review of pharmacology and mechanisms of action of antipsychotic drugs. Mol Psychiatr 10: $79-104$.

Mohn AR, Gainetdinov RR, Caron MG, Koller BH (1999). Mice with reduced NMDA receptor expression display behaviors related to schizophrenia. Cell 98: 427-436.

Nakki R, Koistinaho J, Sharp FR, Sagar SM (1995). Cerebellar toxicity of phencyclidine. J Neurosci 15: 2097-2108.

Nakki R, Nickolenko J, Chang J, Sagar SM, Sharp FR (1996). Haloperidol prevents ketamine- and phencyclidine-induced HSP70 protein expression but not microglial activation. Exp Neurol 137: 234-241.

Olney JW (1994). Neurotoxicity of NMDA receptor antagonists: an overview. Psychopharmacol Bull 30: 533-540.

Olney JW, Farber NB (1994). Efficacy of clozapine compared with other antipsychotics in preventing NMDA-antagonist neurotoxicity. J Clin Psychiatr 55(Suppl B): 43-46.
Olney JW, Labruyere J, Price MT (1989). Pathological changes induced in cerebrocortical neurons by phencyclidine and related drugs. Science 244: 1360-1362.

Olney JW, Labruyere J, Wang G, Wozniak DF, Price MT, Sesma MA (1991). NMDA antagonist neurotoxicity: mechanism and prevention. Science 254: 1515-1518.

Olney JW, Newcomer JW, Farber NB (1999). NMDA receptor hypofunction model of schizophrenia. J Psychiatr Res 33: 523-533.

Radewicz K, Garey LJ, Gentlemen SM, Reynolds R (2000). Increase in HLA-DR immunoreactive microglia in frontal and temporal cortex of chronic schizophrenics. J Neuropathol Exp Neurol 59: 137-150.

Rajdev S, Fix AS, Sharp FR (1998). Acute phencyclidine neurotoxicity in rat forebrain: induction of haem oxygenase-1 and attenuation by the antioxidant dimethylthiourea. Eur $J$ Neurosci 10: 3840-3852.

Richelson E (1999). Receptor pharmacology of neuroleptics: relation to clinical effects. J Clin Psychiatr 60: 5-14.

Salter MW, Kalia LV (2004). Src kinases: a hub for NMDA receptor regulation. Nat Rev Neurosci 5: 317-528.

Sams-Dodd F (1997). Effect of novel antipsychotic drugs on phencyclidine-induced stereotyped behaviour and social isolation in the rat social interaction test. Behav Pharmacol 8: 196-215.

Sharp FR, Butman M, Aardalen K, Nickolenko J, Nakki R, Massa SM et al (1994a). Neuronal injury produced by NMDA antagonists can be detected using heat shock proteins and can be blocked with antipsychotics. Psychopharmacol Bull 30: 555-560.

Sharp FR, Butman M, Koistinaho J, Aardalen K, Nakki R, Massa SM et al (1994b). Phencyclidine induction of the hsp 70 stress gene in injured pyramidal neurons is mediated via multiple receptors and voltage gated calcium channels. Neuroscience 62: 1079-1092.

Sharp FR, Butman M, Wang S, Koistinaho J, Graham SH, Sagar SM et al (1992). Haloperidol prevents induction of the hsp70 heat shock gene in neurons injured by phencyclidine (PCP), MK801, and ketamine. J Neurosci Res 33: 605-616.

Sharp FR, Butman M, Wang S, Koistinaho J, Graham SH, Sagar SM et al (1993). Heat shock proteins used to show that haloperidol prevents neuronal injury produced by ketamine, MK801, and phencyclidine. Ann N Y Acad Sci 679: 288-290.

Sharp FR, Jasper P, Hall J, Noble L, Sagar SM (1991). MK-801 and ketamine induce heat shock protein HSP72 in injured neurons in posterior cingulate and retrosplenial cortex. Ann Neurol 30: 801-809.

Sharp FR, Massa SM, Swanson RA (1999). Heat-shock protein protection. Trends Neurosci 22: 97-99.

Sharp FR, Tomitaka M, Bernaudin M, Tomitaka S (2001). Psychosis: pathological activation of limbic thalamocortical circuits by psychomimetics and schizophrenia? Trends Neurosci 24: $330-334$

Shimizu S, Simon RP, Graham SH (1997). Dimethylsulfoxide (DMSO) treatment reduces infarction volume after permanent focal cerebral ischemia in rats. Neurosci Lett 239: 125-127.

Sprague DA, Loewen PS, Raymond CB (2004). Selection of atypical antipsychotics for the management of schizophrenia. Ann Pharmacother 38: 313-319.

Swerdlow NR, Bakshi V, Waikar M, Taaid N, Geyer MA (1998). Seroquel, clozapine and chlorpromazine restore sensorimotor gating in ketamine-treated rats. Psychopharmacology (Berlin) 140: $75-80$.

Tamminga C (1999). Glutamatergic aspects of schizophrenia. Br J Psychiatr Suppl 37: 12-15.

Tatsumi M, Jansen K, Blakely RD, Richelson E (1999). Pharmacological profile of neuroleptics at human monoamine transporters. Eur J Pharmacol 368: 277-283. 
Tomitaka M, Tomitaka S, Rajdev S, Sharp FR (2000a). Fluoxetine prevents PCP- and MK801-induced HSP70 expression in injured limbic cortical neurons of rats. Biol Psychiatr 47: 836-841.

Tomitaka S, Tomitaka M, Tolliver BK, Sharp FR (2000b). Bilateral blockade of NMDA receptors in anterior thalamus by dizocilpine (MK-801) injures pyramidal neurons in rat retrosplenial cortex. Eur J Neurosci 12: 1420-1430.

Vollenweider FX, Vontobel P, Oye I, Hell D, Leenders KL (2000). Effects of (S)-ketamine on striatal dopamine: a $\left[{ }^{11} \mathrm{C}\right]$ raclopride PET study of a model psychosis in humans. J Psychiatr Res 34: 35-43.

Zhou J, Menko AS (2002). The role of Src family kinases in cortical cataract formation. Invest Ophthalmol Vis Sci 43: 2293-2300. 